\title{
The Effects of Steel Fibre on the Mechanical Strength and Durability of Steel Fibre Reinforced High Strength Concrete (SFRHSC) Subjected to Normal and Hygrothermal Curing
}

\author{
G. Velayutham ${ }^{1}$, C.B. Cheah ${ }^{2, \text { a }}$ \\ ${ }^{1,2}$ School of Housing, Building and Planning, Universiti Sains Malaysia, 11800 Penang, Malaysia
}

\begin{abstract}
This paper presents the experimental investigation into the mechanical strength and durability of steel fibre high strength concrete (SFHSC). In the experimental investigation, the properties of the steel fibre high strength concrete were assessed through two types of curing regimes, the normal water curing and the hygrothermal curing treatment, with the results of the tests being taken at 7 days and 7 days +24 hours. The steel fibres were added at volume fractions of $0.5 \%, 1.0 \%, 1.5 \%, 2.0 \%$ and $3.0 \%$. The tests that were performed for the mechanical strength and durability were the compressive and flexural strength test, the modulus of elasticity test, the ultrasonic pulse velocity test, the water absorption test, the air permeability test and the porosity test. The compressive and flexural strength of the steel fibre high strength concrete reached their maximum of 70.7 $\mathrm{MPa}$ and $11.45 \mathrm{MPa}$, respectively during normal curing for the $3.0 \%$ volume fraction of steel fibre. The experimental results of this study indicate that the inclusion of steel fibres enhances the mechanical strength of high strength concrete cured in normal water curing as compared to the hygrothermal curing treatment.
\end{abstract}

\section{Introduction}

High strength concrete is used in the construction of long span bridges, walkways, piles and high rise structures, and the use of high strength concrete in the construction industry is increasing rapidly [1]. Furthermore, the development of steel fibre reinforced concrete in 1874 by Bernard [2] improved the mechanical performance of concrete. High strength concrete contains more cement and tends to shrink more. The use of Portland cement and a reduction in the water content $(w / c)$ will increase the strength of concrete. Once there is an increase in the strength, the elastic modulus of the concrete will also increase, thereby reducing the creep coefficient. This is why high strength concrete tends to be more prone to resisting pressure than low strength concrete [3]. Besides that, various types of steel fibres have been produced in different geometrical shapes, such as the hooked end, crimped, deformed end and deformed wire, with the most popular type of steel fibre used in the market being the hooked end. Steel fibre has been proven to be the best combination for high strength concrete to produce the highest mechanical strength and durability with regard to the curing time, curing type and the steel fibre geometry $[4,5]$.

\footnotetext{
${ }^{a}$ Corresponding author: cheahcheeban@usm.my
} 
The addition of steel fibre will increase the compressive strength by a certain percentage and will also increase the tensile strength of high strength concrete to potentially produce improvements in the workability of high strength concrete. The compressive strength of steel fibre reinforced concrete usually ranges between $60 \mathrm{MPa}-100 \mathrm{MPa}$ [6]. Song and Hwang [7] stated that the compressive strength increases at the volume fraction of $1.5 \%$ steel fibre used, which means that the highest compressive strength is produced at a volume of $1.5 \%$. As the volume of steel fibre increases to $2 \%$, the compressive strength decreases slightly. Further, the splitting tensile strength of the high strength fibre reinforced concrete increases when there is an increase in the steel fibre volume fraction. It has been found that the relationship between the duration of mixing, the mixing sequence, the volume of steel fibre and the steel fibre geometry has an influence on the segregation of the fibre during mixing.

The addition of steel fibre into a wet concrete matrix can prevent fibre agglomeration because if the mix is too dry or wet it can cause bundling of the steel fibres [8]. For concrete which contains steel fibres, the amount or the volume of the super plasticizer (SP) is used to maintain the flow rate of the fresh mortar mix at around $150 \mathrm{~mm}-160 \mathrm{~mm}$ to ensure good workability. The main purpose of a super plasticizer is to control the water binder ratio and thus reduce the water content during mixing. According to Yao [9], steel fibres give the highest compressive strength, while polypropylene fibres give the lowest compressive strength among the three types of fibres. The super plasticizer is added until a flow rate of $160 \mathrm{~mm}$ is reached. In this research, the addition of steel fibre increased the modulus of rupture while the polypropylene fibre gave the lowest modulus of rupture. The ductility improved with the addition of steel fibre and resulted in an increase in the flexural strength, which was higher than that of the other types of fibres used. The use of short fibres can provide a good bridging effect to resist cracking propagation [7,9]. When cracking occurs as the concrete hardens, the steel fibres are distributed evenly to block the crack. Thus, the inclusion of steel fibres contributes good mechanical strength to the concrete [10]. The incorporation of uniformly distributed short steel fibres increases the void content and decreases the workability of the cement-based materials [11]. Besides that, the increase in the pores volume of steel fibre reinforced concrete will raise the value of the corresponding ultrasonic pulse velocity. In other words, when there is a decrease in the unit weight, there will be an increase in the ultra-pulse velocity of the concrete. When the specimen was tested at 28 days, the average ultra-pulse velocity that was obtained was around $4543 \mathrm{~m} / \mathrm{s}$ for the control mixture or what is known as normal concrete. A relationship exists between the ultrasonic pulse velocity and the unit weight in conventional concrete [12]. The volume and the length of the steel fibres used clearly influence the porosity and the permeability of the concrete.

This study aims to investigate the mechanical performance and durability of steel fibre reinforced concrete containing various volume fractions of fibre subjected to hygrothermal treatment. The knowledge derived is useful for the precast structural element in the manufacturing sector, where accelerated hygrothermal curing is a typical form of post-treatment for rapid strength gain of the concrete elements.

\section{Experimental Setup}

\subsection{Materials and Preparation of Samples}

The steel fibre high strength concrete (SFHSC) was made by using ordinary Portland cement (OPC), fine sand, steel fibres and controlled water content $(w / c)$ in the range of 0.26 . Since the water content was controlled, a super plasticizer (SP) was used and added into the mixture in both normal strength concrete and steel fibre high strength concrete (SFHSC). The super plasticizer was added into the mixture by using cups to maintain the flow at $145 \mathrm{~mm}-155 \mathrm{~mm}$ to ensure a proper subsequent compaction of mix in the steel moulds. The volume per cast was $0.026 \mathrm{~m}^{3}$. The mixture was then poured into the moulds and vibrated by using a vibrating table to perform proper compaction of the mixture for 30 seconds thrice to avoid segregation. The specimens were then allowed to air dry in the laboratory for 1 day, followed by subsequent removal from the moulds. All the tests were carried out by using cubes and prisms only. 


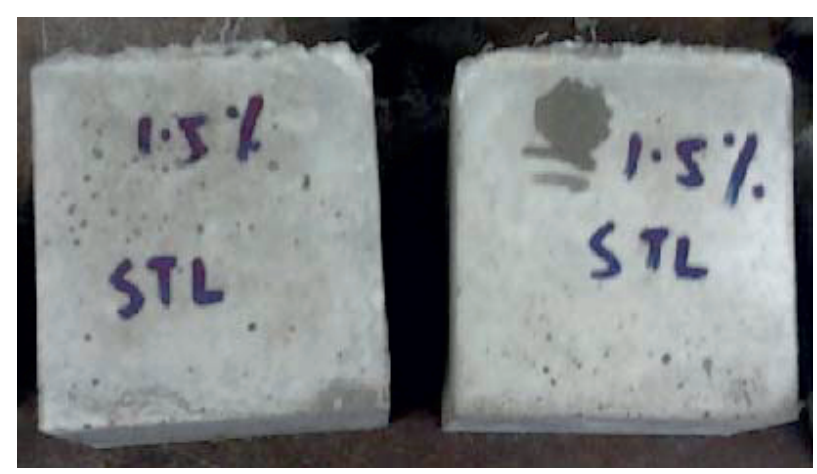

Figure 1. Steel Fibre High Strength Concrete

\subsection{Testing Procedure}

A total of 7 tests were carried out, with the size of the cubes used being 100x100x100mm and the size of the prisms used being 100x100x $500 \mathrm{~mm}$, with a total of 6 cubes and 4 prisms for each batch. The volume of the steel fibres that were used in this research were $0 \%, 0.5 \%, 1.0 \%, 1.5 \%, 2.0 \%$, and $3.0 \%$ to determine the best workability mix.

Table 1. Total cubes and prisms used

\begin{tabular}{ccccc}
\hline Steel fiberVolume, $\mathbf{f} f$ & $\begin{array}{l}\text { Normal } \\
\text { curing } \\
\text { Cubes }\end{array}$ & $\begin{array}{l}\text { Normal } \\
\text { curing } \\
\text { Prism }\end{array}$ & $\begin{array}{l}\text { Hygrothermal } \\
\text { Curing } \\
\text { Cubes }\end{array}$ & $\begin{array}{l}\text { Hvgrothermal } \\
\text { Curing } \\
\text { Prism }\end{array}$ \\
\hline 0 & 3 & 2 & 3 & 2 \\
0.5 & 3 & 2 & 3 & 2 \\
1.0 & 3 & 2 & 3 & 2 \\
1.5 & 3 & 2 & 3 & 2 \\
2.0 & 3 & 2 & 3 & 2 \\
3.0 & 3 & 2 & 3 & 2 \\
\hline TOTAL & 18 & 12 & 18 & 12 \\
\hline
\end{tabular}

In addition, the curing regime was fixed to only two types, the 7-day normal curing followed by hygrothermal curing. Hygrothermal curing was performed by placing the mortar specimen into a hot water bath for 24 hours after the 7-day normal curing at $70^{\circ} \mathrm{C}$, which was the optimum temperature under the curing condition. This curing method was performed to obtain and determine the differences between the mechanical strength and the durability under both curing conditions.

\subsection{Mechanical Properties}

The compressive strength of the steel fibre high strength concrete was tested on the 100x100x100mm cubes for both the 7 days normal curing and the 7 days +24 hours hygrothermal curing. A total of 3 cubes were tested for both curing regimes. Once the concrete cubes had been removed from the water after the specified curing time, the surfaces of the cubes were wiped and sprayed using air pressure to remove excess water. The concrete cubes were then placed on a compression machine and aligned to the centre so that the load would be balanced on the surface during compression. The machine was set at a low compression speed, and the compressive strength was tested and the results recorded. Further testing procedures were carried out as a benchmark and were based on the ASTM C109-93. The flexural strength of the steel fibre high strength concrete was tested on the 100x100x500mm prisms for both 7 days and 7 days +24 hours of hygrothermal curing. A total of 2 prisms were tested for both curing regimes. The flexural strength test was performed for the whole steel fibre volume that was used. The flexural strength of the steel fibre high strength 
concrete was calculated on the average of the maximum load provided by the 2 prisms. The flexural test method performed was based on ASTM standards. The dynamic modulus was tested on different volumes of the steel fibre batches using the $100 \times 100 \times 500 \mathrm{~mm}$ prisms. The instrument used to measure the dynamic modulus was the dynamic accelerometer, where the weight of the prism was taken and recorded. The values of the weight, length, and the thickness of the prism were inserted into the Emeter and tested. The dynamic modulus of elasticity was determined based on the (ASTM C215) standards. This test was performed more than twice until a constant value was obtained. The dynamic modulus was calculated using Equations 1 and 2, where $M$ is the weight of the specimen $(\mathrm{Kg})$ and $L$ is the length of the specimen $(\mathrm{m})$

$$
\begin{aligned}
& E_{d}=D M n^{2} \\
& D=\frac{4 L}{b t}
\end{aligned}
$$

The ultrasonic pulse velocity test (UPV) was performed on different volumes of steel fibre using the $100 \times 100 \times 500 \mathrm{~mm}$ prisms. The test was conducted using 2 prisms for each batch. A constant path length of $500 \mathrm{~mm}$ between transducers was used to obtain the transmission of ultrasonic pulse velocity under direct transmission. To obtain accurate and consistent results, grease was applied to the transducers and also to the surface of the steel fibre concrete. The results were taken several times until a constant result was obtained. The test was performed on both the $\mathrm{X}$-axis and the $\mathrm{Y}$-axis of the concrete with dimensions of $500 \mathrm{~mm}$ and $100 \mathrm{~mm}$, respectively.

\subsection{Durability}

The coring technique was performed on broken prism specimens that were used in the flexural strength test. Four mortar cylinders were cored from two $75 \mathrm{~mm}$ and two $50 \mathrm{~mm}$ prism samples. The $75 \mathrm{~mm}$ cored sample was used for the water absorption test while the $50 \mathrm{~mm}$ sample was used for both the air permeability test and the porosity test. The water absorption test was performed using the $75 \mathrm{~mm}$ cored sample. Three $75 \mathrm{~mm}$ samples were cored from each prism. After coring, the sample was weighed and the data was recorded. The sample was then placed in the oven for about 2-3 days until the weight of the sample became constant. The sample was then removed from the oven and placed at room temperature to cool. Then, the water absorption test was performed by submerging the sample in water for 30 minutes. After 30 minutes, the sample was wiped and weighed again, and the data was recorded. This test procedure was carried out based on the BS 1881: Part 122 (1983). The water absorption was then calculated based on Equation 3,

$$
\text { Water absorption }(\%)=\frac{W_{s}-W_{d}}{W_{d}} \times 1.09 \times 100
$$

where $W_{d}=$ the weight of the oven dried specimen $(\mathrm{g})$, and $W_{\alpha}=$ the weight of the sample after immersion in water for 30 minutes.

The air permeability test was performed on the $50 \mathrm{~mm}$ cylinder core sample. The $50 \mathrm{~mm}$ sample was then marked in the centre point and cut into half. The test was performed for both curing regimes. Once the sample had been cut into half, it was put into the oven until a stable weight was obtained. The diameter and length of the sample were recorded. The gas pressure of the permeameter was set to 1 bar. The permeability value was calculated based on Equation 4,

$$
k=\frac{2 P_{2} v \ell \times 1.76 \times 10^{-5}}{A\left(P_{1}^{2}-P_{2}^{2}\right)}
$$

where $k=$ the intrinsic permeability $\left(\mathrm{m}^{2}\right), v=$ the flow rate $\left(\mathrm{m}^{3} / \mathrm{s}\right), \mathrm{A}=$ the cross-sectional area $\left(\mathrm{m}^{2}\right)$, $\ell=$ the length of the porous media $(\mathrm{m}), \boldsymbol{P}_{1}=$ the absolute applied pressure $(\mathrm{Pa})$ and $\boldsymbol{p}_{2}=$ the pressure of the flow rate $(\mathrm{Pa})$. 
A porosity test was performed on the sample which was used in the air permeability test. The porosity test was performed for both the normal and hygrothermal curing for the different volumes of steel fibres used. The porosity value was calculated based on Equation 5,

$$
P(\%)=\frac{\left(W_{a}-W_{d}\right)}{\left(W_{a}-W_{w}\right)} \times 100
$$

where $W_{d}=$ the dry weight of the sample $(\mathrm{g}), W_{w}=$ the weight in water $(\mathrm{g})$ and $W_{a}=$ the weight in air (g).

\section{Results and Discussion}

A total of 7 tests were performed on both the mechanical properties and the durability. The results were obtained based on experimental observations of both the normal and hygrothermal curing regimes.

\subsection{Compressive Strength Test}

Table 2 and Table 3 show the compressive strength of steel fibre high strength concrete (SFHSC) and normal strength concrete for both normal and hygrothermal curing. For the normal curing regime, the volume fraction of $3.0 \%$ steel fibre gave the highest compressive strength of $70.7 \mathrm{MPa}$. As the volume of the fibres increased, the compressive strength increased significantly. Table 3 shows the compressive strength with the hygrothermal curing regime. A comparison between the normal and hygrothermal curing revealed that the normal curing provided better strength than the hygrothermal curing for different volumes of steel fibres used, where with hygrothermal curing the strength dropped after 7 days +24 hours.

Table 2. Compressive strength of SFHSC and NSC (Normal Curing)

\begin{tabular}{cccc}
\hline $\begin{array}{c}\text { Steel Fiber Volume } \\
(\%)\end{array}$ & $\begin{array}{c}\text { Compressive strength } \\
\text { (MPa) }\end{array}$ & $\begin{array}{c}\text { Strength Effectiveness } \\
(\%)\end{array}$ & $\begin{array}{c}\text { Flowtest } \\
(\mathrm{mm})\end{array}$ \\
\hline & & & \\
0 & 45.2 & 0 & 150 \\
0.5 & 51.3 & 13.5 & 147 \\
1.0 & 56.9 & 25.9 & 150 \\
1.5 & 59.8 & 32.3 & 155 \\
2.0 & 61.7 & 36.5 & 145 \\
3.0 & 70.7 & 56.4 & 150 \\
\hline
\end{tabular}

Table 3. Compressive strength of SFHSC and NSC (Hygrothermal Curing)

\begin{tabular}{cccc}
\hline $\begin{array}{c}\text { Steel Fiber Volume } \\
(\%)\end{array}$ & $\begin{array}{c}\text { Compressive strength } \\
(\mathrm{MPa})\end{array}$ & $\begin{array}{c}\text { Strength Effectiveness } \\
(\%)\end{array}$ & $\begin{array}{c}\text { Flowtest } \\
(\mathrm{mm})\end{array}$ \\
\hline & & & \\
0 & 50.1 & 0 & 150 \\
0.5 & 49.5 & -1.2 & 147 \\
1.0 & 53.9 & 7.6 & 150 \\
1.5 & 55.4 & 10.6 & 155 \\
2.0 & 58.9 & 17.6 & 145 \\
3.0 & 64.1 & 27.9 & 150 \\
\hline
\end{tabular}

\subsection{Flexural Strength Test}

Table 4 and Table 5 show the flexural strength with both normal and hygrothermal curing for the steel fibre high strength concrete (SFHSC) and normal strength concrete. For the normal curing 
regime, the volume fraction of $3.0 \%$ steel fibre gave the highest flexural strength of $11.45 \mathrm{MPa}$. As the volume of the fibres increased, the flexural strength increased significantly. Table 4 shows the flexural strength with the hygrothermal curing regime. When the normal curing was compared to the hygrothermal curing, it was found that the normal curing provided better flexural strength with the use of different volumes of steel fibres, where the strength with hygrothermal curing dropped after 7 days +24 hours. With steel fibre volumes of $2.0 \%$ and $3.0 \%$, the hygrothermal curing resulted in higher flexural strength than the normal strength concrete.

Table 4. Flexural strength of SFHSC and NSC (Normal Curing)

\begin{tabular}{cccc}
\hline $\begin{array}{c}\text { Steel Fiber Volume } \\
(\%)\end{array}$ & $\begin{array}{c}\text { Flexural strength } \\
(\mathrm{MPa})\end{array}$ & $\begin{array}{c}\text { Strength Effectiveness } \\
(\%)\end{array}$ & $\begin{array}{c}\text { Flowtest } \\
(\mathrm{mm})\end{array}$ \\
\hline & & & \\
0 & 5.52 & 0 & 150 \\
0.5 & 6.08 & 10.1 & 147 \\
1.0 & 6.44 & 16.7 & 150 \\
1.5 & 7.11 & 28.8 & 155 \\
2.0 & 8.69 & 57.4 & 145 \\
3.0 & 11.45 & 107.4 & 150 \\
\hline
\end{tabular}

Table 5. Flexural strength of SFHSC and NSC (Hygrothermal Curing)

\begin{tabular}{cccc}
\hline $\begin{array}{c}\text { Steel Fiber Volume } \\
(\%)\end{array}$ & $\begin{array}{c}\text { Flexural strength } \\
\text { (MPa) }\end{array}$ & $\begin{array}{c}\text { Strength Effectiveness } \\
(\%)\end{array}$ & $\begin{array}{c}\text { Flowtest } \\
(\mathrm{mm})\end{array}$ \\
\hline & & & \\
0 & 6.55 & 0 & 150 \\
0.5 & 4.55 & -30.5 & 147 \\
1.0 & 4.99 & -23.8 & 150 \\
1.5 & 5.12 & -21.8 & 155 \\
2.0 & 8.10 & 23.7 & 145 \\
3.0 & 10.71 & 63.5 & 150 \\
\hline
\end{tabular}

\subsection{Dynamic Modulus of Elasticity Test}

For normal strength concrete the dynamic modulus will be in the range $>30 \mathrm{Gpa}$. The dynamic modulus tendency is dependent on the weight, length and height of the concrete. For the steel fibre high strength concrete, the dynamic modulus was in the range of $40 \mathrm{Gpa}$ to $43 \mathrm{GPa}$ for the normal curing regime. The average of the result was obtained from 2 prisms for each batch of steel fibre volume. Table 6 shows the dynamic modulus results.

Table 6. Dynamic Modulus of SFHSC and NSC (Normal and Hygrothermal Curing)

\begin{tabular}{ccc}
\hline \multirow{2}{*}{\begin{tabular}{c} 
Steel $\begin{array}{c}\text { Fiber Volume } \\
\text { (\%) }\end{array}$ \\
\cline { 2 - 3 }
\end{tabular}} & \multicolumn{2}{c}{ Dynamic Modulus Of Elasticity (GPa) } \\
\cline { 2 - 3 } & Normal curing & Hygrothermal curing \\
\hline 0 & 37.9 & 37.7 \\
0.5 & 39.4 & 39.1 \\
1.0 & 41.9 & 40.2 \\
1.5 & 42.2 & 39.6 \\
2.0 & 41.0 & 40.2 \\
3.0 & 42.2 & 41.5 \\
\hline
\end{tabular}




\subsection{Ultrasonic Pulse Velocity (UPV) Test}

The Ultrasonic pulse velocity test was performed on 2 prisms for each batch of steel fibre volume content. The results for the UPV in both $x-x$ axis and $y-y$ axis are shown in Table 7 . The average value for the UPV test for the controlled concrete was in the range of $4300 \mathrm{~m} / \mathrm{s}$ to $4500 \mathrm{~m} / \mathrm{s}$.

Table 7. Ultrasonic Pulse Velocity of SFHSC and NSC (Normal and Hygrothermal Curing)

\begin{tabular}{|c|c|c|c|c|}
\hline \multirow{3}{*}{$\begin{array}{l}\text { Steel Fiber Volume } \\
(\%)\end{array}$} & \multicolumn{4}{|c|}{ Ultrasonic Pulse Velocity $(\mathrm{m} / \mathrm{s})$} \\
\hline & \multicolumn{2}{|c|}{ Normal curing } & \multicolumn{2}{|c|}{ Hygrothermal curing } \\
\hline & $x-x$ & $y-y$ & $x-x$ & $y-y$ \\
\hline 0 & 4365 & 4466 & 4334 & 4420 \\
\hline 0.5 & 4472 & 4512 & 4417 & 4415 \\
\hline 1.0 & 4484 & 4565 & 4440 & 4484 \\
\hline 1.5 & 4454 & 4425 & 4436 & 4366 \\
\hline 2.0 & 4390 & 4405 & 4365 & 4475 \\
\hline 3.0 & 4531 & 4598 & 4523 & 4562 \\
\hline
\end{tabular}

\subsection{Water Absorption Test}

The water absorption test for the steel fibre high strength concrete was performed on the $75 \mathrm{~mm}$ cylinder cored sample. As the steel fibre volume fraction increased in the normal curing regime, the percentage of the water absorption decreased. Table 8 shows the water absorption results:

Table 8. Water Absorption of SFHSC and NSC (Normal and Hygrothermal Curing)

\begin{tabular}{ccc}
\hline \multirow{2}{*}{$\begin{array}{c}\text { Steel Fiber Volume } \\
(\%)\end{array}$} & \multicolumn{2}{c}{ Water absorption (\%) } \\
\cline { 2 - 3 } & Normal curing & Hygrothermal curing \\
\hline & & \\
0 & 3.30 & 2.73 \\
1.0 & 2.69 & 1.95 \\
1.5 & 2.60 & 2.05 \\
2.0 & 2.53 & 2.13 \\
3.0 & 2.49 & 2.22 \\
& 2.46 & 2.26 \\
\hline
\end{tabular}

\subsection{Air Permeability Test}

The air permeability test was carried out on the $50 \mathrm{~mm}$ sample when it was cut into half. The permeability value was given by the penetration of pressured gas into the sample. The air permeability value for the normal strength concrete was around 21 seconds per $10 \mathrm{~cm}$ measurement, as shown in Table 10 .

Table 9. Air Permeability of SFHSC and NSC (Normal and Hygrothermal Curing)

\begin{tabular}{ccc}
\hline \multirow{2}{*}{$\begin{array}{c}\text { Steel Fiber Volume } \\
\text { (\%) }\end{array}$} & \multicolumn{2}{c}{ Air permeabilityvalue (sec) } \\
\cline { 2 - 3 } & Normal curing & Hygrothermal curing \\
\hline 0 & 21.65 & 24.34 \\
0.5 & 66.68 & 58.46 \\
1.0 & 54.97 & 49.35 \\
1.5 & 40.31 & 37.11 \\
2.0 & 27.38 & 25.46 \\
3.0 & 28.57 & 27.55 \\
\hline
\end{tabular}




\subsection{Porosity Test}

The porosity of the normal controlled concrete was in the range of $14.4 \%$ for the 7 -day normal curing compared to the hygrothermal curing, which resulted in a porosity of $14.04 \%$ for the controlled concrete. Therefore, the addition of $0.5 \%$ volume of steel fibre resulted in a porosity of $9.66 \%$ in the normal curing regime. The concrete with steel fibres had a lower porosity value when compared to the normal controlled concrete. In the normal curing regime, as the steel fibre volume increased, the porosity increased by a lower percentage. Table 10 shows the average porosity value for the SFHSC that was subjected to both curing regimes.

Table 10. Porosity of SFHSC and NSC (Normal and Hygrothermal Curing)

\begin{tabular}{ccc}
\hline \multirow{2}{*}{$\begin{array}{c}\text { Steel Fiber Volume } \\
\text { (\%) }\end{array}$} & \multicolumn{2}{c}{ Porosity value (\%) } \\
\cline { 2 - 3 } & Normal curing & Hygrothermal curing \\
\hline 0 & 14.37 & \\
0.5 & 9.66 & 14.04 \\
1.0 & 9.81 & 11.87 \\
1.5 & 12.29 & 11.61 \\
2.0 & 13.15 & 12.15 \\
3.0 & 14.22 & 12.62 \\
& & 13.53 \\
\hline
\end{tabular}

\section{Conclusions and Recommendations}

The following conclusions can be derived from the experimental investigation.

1. The incorporation of steel fibre into high strength concrete increases the compressive strength and the flexural strength of the concrete.

2. The maximum compressive strength and flexural strength of $70.7 \mathrm{MPa}$ and $11.45 \mathrm{MPa}$, respectively are attained at a steel fibre volume fraction of $3.0 \%$.

3. Steel fibre high strength concrete (SFHSC) shows good mechanical behaviour and compressive strength in normal water curing compared to hygrothermal curing.

4. Normal strength concrete shows an increase in the compressive and flexural strength with hygrothermal curing.

5. It has been found that steel fibre high strength concrete (SFHSC) is not suitable for hygrothermal curing compared to normal strength concrete.

6. Steel fibre high strength concrete shows improved durability compared to normal concrete.

7. The mechanical properties and durability of steel fibre high strength concrete are expected to increase if it is sustained in normal water curing for the testing period of 28 days.

\section{References}

1. E.N. Antoine, Fiber Reinforcement for Concrete, Concrete International, 8 (1985) 21-29

2. B. Miloud, Permeability and Porosity Characteristic of Steel Fiber Reinforced Concrete, Asian Journal Of Civil Engineering (Building and Housing), 6 (2005) 317-330.

3. G. Idorn, Durability of Concrete, 1992.

4. A.S. Ezeldin and P.N. Balaguru, Normal and High Strength Fiber Reinforced Concrete Under Compression, Journal of Materials in Civil Engineering, 10(1992) 415-429.

5. B.P. Hughes and N.I Fatuhu, Workability of Steel Fiber Reinforced Concrete, 1977.

6. S. Tokgoz, C. Dunbar, K. Tarinkulu, Experimental Behavior of Steel Fiber High Strength Reinforced Concrete and Composites Columns, Journal of Construction Steel Research 74 (2012) 98-107. 
7. P.S Song and S. Hwang, Mechanical Properties of High Strength Fiber Reinforced Concrete, Construction and Building Materials, 18(9) (2004) 669-673

8. R.N. Swamy, The Technology of Steel Fiber Reinforced Concrete for Practical Applications. ICE Proceedings 56(2) 143-159.

9. W. Yao, L. Jie, K. Wu, Mechanical Properties of Hybrid Fiber Reinforced Concrete at Low Fiber Volume, Cement \& Concrete Research 33 (2003) 27-30.

10. Q. Chunxiang, I. Patnaikumi, Properties of High Strength Steel Fiber Reinforced Beams in Bending, Cement and Concrete Composite 21(1) (1999) 73-81.

11. J. Edgington, D.J. Hannat, R.I. Williams, Steel Fiber Reinforced Concrete, Building Research Establishment Current Paper CP 69/74 (1974), British Research Establishment, Department of the Environment, pg 17.

12. S. Yacizi, G. Inan and T. Volkan, Effect of Aspect Ratio and Volume of Steel Fiber on the Mechanical Properties of Steel Fiber Reinforced Concrete. Construction And Building Material 21(6) (2007) 1250-1253.

13. ASTM C215, Standard Test Method for Fundamental Transverse, Longitudinal and Torsional Frequencies of Concrete Specimen, Annual Book of ASTM Standards, American Society of Testing and Materials, 1991.

14. ASTM C109, Compressive strength of mortars, Annual Book of ASTM Standards, American Society of testing and materials, 1993.

15. ACI 544.1R, State of the Art Report on Fiber Reinforced Concrete, American Concrete Institute, Farmington Hills, Michigan, 1996. 